\title{
Drug Nano-particle: A Release Kinetics
}

Roli Jain*, Sandeep Kumar Sukla, Neeti Nema and Archna Panday

Department of Chemistry, Dr. Hari Singh Gour University, Sagar, Madhya Pradesh, India

\begin{abstract}
Depression is estimated to affect nearly 340 million people worldwide and 18 million people in the US at any given time making it the third most costly and disabling illness in the US. Duloxetine hydrochloride is one of the main antidepressant used as a selective serotonin and nor epinephrine reuptake inhibitor (SSNRI) for oral administration. As it works on central nervous system (CNS), drug should be more available to the cells. To increase the efficacy and solubility drug can be formulated with polymers using nano particle as a drug carriers. In this work we propose and analyzed different approaches to study measuring the size of nano particle and effect of these nano particles on the in vitro kinetics dissolution behavior. The drug obeyed the beers law over the range of $5-50 \mu \mathrm{g} / \mathrm{ml}$ at $\lambda \mathrm{max} 230 \mathrm{~nm}$. Drug with PEG 4000 in 6.8 phosphate buffer is proposed good discriminative dissolution media for Duloxitine hydrochloride delayed release formulation. The quantization of drug release studied by UV-Spectrophotometer at $230 \mathrm{~nm}$. Nano particle size and morphology are determined by Scanning Electron Microscopy (SEM) and Transmission Electron Microscopy (TEM). By fitting the dissolution data in various kinetic models find out delayed release formulation of Duloxitine hydrochloride obey the Higuchi model kinetics having linearity range 0.99 and release component ' $n$ ' obtain by the Korsmyer Pappas model indicate release mechanism followed by the anomalous diffusion process.
\end{abstract}

Keywords: Delayed release kinetics; Duloxitine hydrochloride; Korsmyer peppas model; Nanoparticle; Transmission electron microscopy; Scanning electron microscopy

\section{Introduction}

18 million individuals within the North American nation at any given time [1,2], creating it the third most expensive and disabling health problem within the North American nation [3-8]. By the year 2020, it's foretold that depressive health problem are going to be the second leading reason for incapacity worldwide [9]. An array of studies has documented the big impact of this draining condition on each patient and therefore the health care system [10]. Duloxitine coordination compound may be a selective serotonin neurotransmitter and nor vasoconstrictor re-uptake matter (SSNRI) for oral administration. Serotonin neurotransmitter (5-HT) and nor vasoconstrictor (NE) a neurotransmitters thought to assist regulate human emotions and sensitivity to pain (Figure 1) [11].

Formulation of poorly water soluble medication through the standard technique is incredibly difficult and tremendous tasks for the pharmaceutical industry. Someone owing to low effectiveness of this medication. The poor bioavailability of poorly soluble molecules that aren't permeation-rate restricted is attributed to dissolution-rate dynamics. The dissolution rate is directly proportional to the expanse of the drug, in step with the Noyes-Whitney model for dissolution dynamics. Applied science is develop, new hope, the tools and technology to figure at atomic, molecular and supramolecular levels resulting in creation of devices and delivery systems with basically new properties and functions. A nanocarrier offers variety of benefits creating it a perfect drug delivery vehicle [12].

- If the bioavailability of a poorly soluble compound is dissolution-rate restricted, approaches that afford delivery victimization nanometer-sized particles of drug improve bioavailability by enhancing dissolution rate.

- This maximizes the quantity of soluble drug that's unengaged to be absorbed. This can be very true for poorly soluble compounds absorbed at an outlined region of the channel.

- Nano carriers will higher deliver medication to small areas inside the body.
- Nano carriers overcome the resistance offered by the physiological barriers within the body as a result of economical delivery of drug to varied elements of the body is directly stricken by particle size.

- Nano carriers aid in economical drug delivery to enhance binary compound solubility of poorly soluble medication that enhance bioavailability for regular Release of drug molecules, and precise drug targeting.

- The surface properties of nano carriers is changed for targeted drug delivery e.g. tiny molecules, proteins, peptides, and nucleic acids loaded nanoparticles aren't recognized by system and expeditiously targeted to specific tissue sorts [13].

Duloxitine hydrochloride (Figure 1) is a poorly soluble drug, bioavailability and efficacy is also less so the purpose of present study determines the size of nanoparticles and studies the in-vitro release kinetics of drug in present of nano carriers $[14,15]$.

Duloxitine hydrochloride is a poorly soluble drug, bioavailability and efficacy is also less so the purposes of present study determine the size of nanoparticles and study the in-vitro release kinetics of drug in present of nano carriers $[14,16]$.

\section{Material and Methods}

The Duloxitine Drug obtained from Glenmark Pharmaceutical as a gift sample and alcohol, PEG-4000, PVP44000 were purchase from Aldrich Chemical. All different reagents Associate with my experiment were used an analytical grade. Whole experiment has been style as per following steps.

${ }^{*}$ Corresponding author: Roli Jain, Department of Chemistry, Dr. Hari Singh Gour University, Sagar, Madhya Pradesh 470003, India, Tel: 91-75822-65810; E-mail: Roli.92@rediffmail.com

Received May 26, 2015; Accepted July 29, 2015; Published October 01, 2015

Citation: Jain R, Sukla SK, Nema N, Panday A (2015) Drug Nano-particle: A Release Kinetics. J Nanomed Nanotechnol 6: 317. doi:10.4172/2157-7439.1000317

Copyright: (c) 2015 Jain R, et al. This is an open-access article distributed under the terms of the Creative Commons Attribution License, which permits unrestricted use, distribution, and reproduction in any medium, provided the original author and source are credited. 


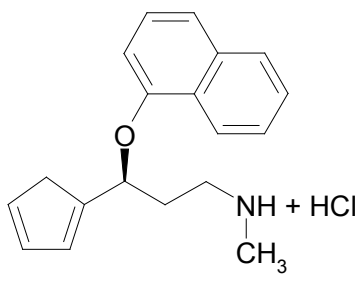

Figure 1: Chemical structure of Duloxitine Hydrochloride

\section{Determination of $\lambda_{\text {max }}$}

Prepare the $10 \mu \mathrm{g} / \mathrm{mL}$ solution of pure drug of Duloxetine Hydrochloride and therefore the absorbance scanned over the vary of wavelength from $200 \mathrm{~nm}$ to $400 \mathrm{~nm}$ (UV vary, Shimazdu ultraviolet (1700)). The obtained $\lambda_{\max }$ was placed at $230 \mathrm{~nm}$.

\section{Preparation of nanoparticles with mixture of PEG 4000}

Nano particles were prepared by the nano precipitation technique this system supported the precipitation and resultant natural process of chemical compound at the interface of solvent and a non solvent. Prepare the four Different samples with the different ratio of Drug, Polymer and stabilizer accordingly that is PEG: PVA: duloxitine to obtain better combination of nanoparticle system. Weigh about $50 \mathrm{mg}$ of drug were dissolve in a very $25 \mathrm{ml}$ of solvent. Dissolve $0.004 \mathrm{~g}$ PEG 4000 and $0.044 \mathrm{~g}$ of PVP $44000 \mathrm{in} 100 \mathrm{ml}$ water for getting ready the chemical compound answer in binary compound part. The organic solution containing drug pores within the $100 \mathrm{ml}$ solution of polymer and stabilizer. This method prepares the little droplets. Finally obtained solution were homogenized by exploitation high speed homogenizer at $21000 \mathrm{pm}$ for $15 \mathrm{~min}$ and therefore the organic part absolutely take away exploitation turning vacuum evaporization at $40^{\circ} \mathrm{C}$ water by Vacuum rotated evaporator and lyophilized with a freeze appliance. The lyophilized powder was collected and store in a cool and dry atmosphere [17].

\section{Determination of encapsulated drug}

The encapsulation efficiency of DOX in lyophilized sample was determined by HPLC that is very accurate and precise separation technique for assay determination. Prepared a $20 \mu \mathrm{g} / \mathrm{ml}$ standard solution of Duloxitine hydrochloride with potency $99.8 \% \mathrm{w} / \mathrm{v}$ in alcohol. Prepared also a sample solution with concentration $20 \mu \mathrm{g} /$ $\mathrm{ml}$ by lyophilized powder in same solvent. Injected $20 \mu \mathrm{g} / \mathrm{ml}$ of each solution in HPLC and scan all the results using PDA-UV detector. The quantity of encapsulated drug was calculated by the following subsequent equation [18].

\section{$\mathrm{IE}=\mathrm{AT} / \mathrm{AS} \times \mathrm{Sc} / \mathrm{Tc} \times \mathrm{PE} / 100$}

$\mathrm{AT}=$ Area of test solution.

AS=Area of Standard solution in $\mu \mathrm{g} / \mathrm{ml}$

$\mathrm{Sc}=$ Concentration of standard solution

$\mathrm{St}=$ Concentration of sample answer in $\mu \mathrm{g} / \mathrm{ml}$

IE\% Total amount of Encapsulated Drug

\section{Particle size analysis}

The Particle size of all the samples were determined by the photon co-relation spectroscopy using zeta seizer 2000 Malvern instrument.
Samples of n-DOX were diluted with water for analysis and calculated variance for every determination. Poly inequality Index: poly disparity index was confirm by exploitation the subsequent equation

$$
\mathrm{PI}=\mathrm{D}(09)-\mathrm{D}(0.1) / \mathrm{D}(0.5)
$$

Where $\mathrm{D}(0.9)=$ Particle size right away on top of ninetieth of the sample.

$\mathrm{D}(0.5)=$ particle size right away on top of five hundredth of the sample.

$\mathrm{D}(0.1)=$ particle size right away on top of 100 percent of the sample.

Transmission Electron Microscopy (TEM): The morphology of n-DOX confirm by the Transmission Electron Microscopy CM10 Philips-Netherlands. Before the analysis sample were treated by $0.5 \%(\mathrm{w} / \mathrm{v})$ phosphotungastic acid and glued on a copper grid for observation.

Scanning Electron Microscopy (SEM): The size and morphology are scanning through scanning microscopy. In the SEM setup the nano particulated sample n-DOX coated with platinum as a semiconducting is scanned in a very high chamber with a targeted electromagnetic wave.

Fourier Transforms Infrared (FT-IR) spectroscopy: The FT-IR of $\mathrm{n}$-DOX determined by the Perkin Elmer Norwalk CT photometer, each sample of $\mathrm{n}$-DOX and potassium bromide was mixed in quantitative ratio of 1:100 and compress into a thin film. The base line correction was performing by dried potassium bromide thin film each sample was scan under the range of $400-4000 \mathrm{~cm}^{-1}$ each sample was recorded in triplicate.

\section{In-vitro drug-release}

USP-I (basket) Apparatus was used for the comparative study invitro Release of DOLX, $\mathrm{n}$ DOX and a marketed formulation. Equivalent to $20 \mathrm{mg}$ of drug pore in a vessel containing $500 \mathrm{ml}$ dissolution media (media-pH 6.8 dihydrogen phosphates) set all require dissolution parameter. Withdrawn the $10 \mathrm{ml}$ Aliquot at the time interval of 05,10 , $20,30,40,50,60,70,90,100,120$, min withdrawn sample were replace with same amount of the fresh dissolution medium that's equilibrated at same temperature. Sample were filter through the $0.22 \mu$ syringe filter . further diluted the sample and quantify the concentration of drug by HPLC analysis exploitation Princeton $(250 \times 4.6) 5 \mu \mathrm{L} 1$ packing column with mixture of $0.05 \mathrm{~m}$ ammonium acetate buffer (PH 6.0) and acetonitrile in ratio of (60:40) w/v. Injected $20 \mu$ of every sample and maintain the of column at $30^{\circ} \mathrm{C}$. Analyzed each sample in duplicate at $230 \mathrm{~nm}$ the dissolution were performed in $\mathrm{n}=6$. Calculate the concentration of drug throughout the drug Release and validate the dissolution technique $[19,20]$.

\section{Results and Discussion}

The maximum absorbance of DOX obtained at $\lambda_{\max } 230 \mathrm{~nm}$. The Beer Lambert's law was obeyed in the concentration range 2-25 $\mu \mathrm{g} /$ $\mathrm{ml}$. It is confirmed by linear regression data that was obtained 0.9990 .

Data obtained from the determination of beer's Lambart law provide working range of drug molecule. It is helpful for further designing of experiment during the study.

The results of FT-IR spectrum shown in Figure 2a that result show The mostly FTIR bands of the drug stay intact in each the spectra of the drug and n-DOX $1490 \mathrm{~cm}^{-1}$ : for thiophene ring 3000-3001 cm $\mathrm{cm}^{-1}$ : for aromatic olefin nucleon $(\mathrm{C}=\mathrm{C}-\mathrm{H}) 1400-1600 \mathrm{~cm}^{-1}$ : for aromatic olefin $(\mathrm{C}=\mathrm{C})$ 1000-1300 $\mathrm{cm}^{-1}$ : ether $(\mathrm{C}-\mathrm{O}) 1080-1360 \mathrm{~cm}^{-1}$ : for $\mathrm{C}-\mathrm{N}$ bond. This characteristic band area unit gifts within the FTIR spectrum, 

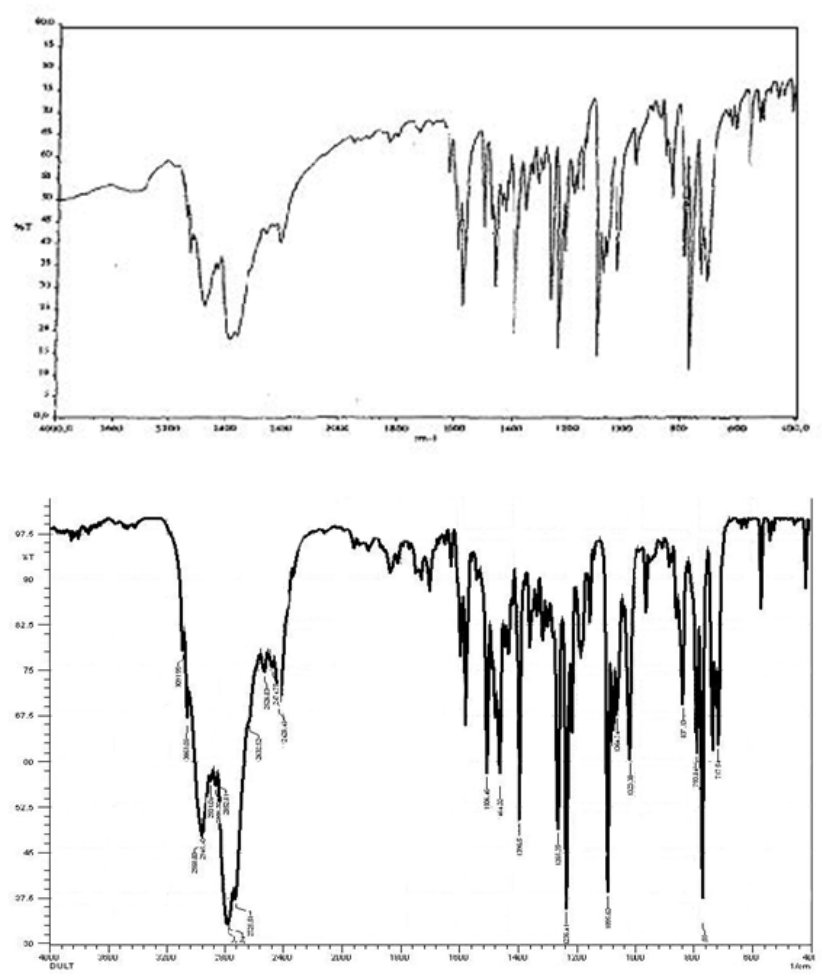

Figure 2: (a) Reference IR Spectrum of DOX (b) IR Spectrum of $n$ DOX.

\begin{tabular}{|l|c|c|c|}
\hline Formulation & $\begin{array}{c}\text { Mean particle size } \\
\text { (um) }\end{array}$ & $\begin{array}{c}\text { Poly dispersity } \\
\text { Index }\end{array}$ & $\begin{array}{c}\text { Encapsulation } \\
\text { efficiency }\end{array}$ \\
\hline DOX & 5201 & 1.49 & - \\
\hline DOX:1:1:1 & Dox-1 531 & 0.79 & $79.2 \%$ \\
\hline DOX:1:2:2 & Dox-2 275 & 0.64 & $84.0 \%$ \\
\hline DOX:1:5:5 & Dox-3 198 & 0.43 & $94.2 \%$ \\
\hline DOX:1:10:10 & Dox-4 100 & 0.30 & $99.1 \%$ \\
\hline
\end{tabular}

Table 1: Result of particle size, poly dispersity index and encapsulation efficiency.

confirming the presence of the drug in its original structure within the $\mathrm{n}$-DOX and protective drug effectively shown in Figure $2 \mathrm{~b}$.

Nanoparticle were prepare by the Nano precipitation technique using different ratio of drug stabilize polymer in to all formulation were found to a white and powdery in appearance [21].

Mean particle size polydispersity Index and encapsulation efficiency of n-DOX with different weight ratio of DOX: PVP PEG were calculated and summarized under the Table 1.

Obtained result (Table 1) show the particle size and PI of DOX is less than $100 \mu \mathrm{m}$ and 0.30 . Severally that result indicate the out of stabilizer and compound has been result on the property of the nanoparticle it the concentration of stabilizer is to 100 (DOX-1) thus it couldn't give comfortable stable system. These result also indicate that the tiny close to size and PI valve will rely upon the number of stabilize and compound. It additionally scale back the particle size of the sample it ended the mix nDOX-4 was comfortable to stabilize the nanoparticle system. The encapsulation potency was resulted beneath (Figure 2).

The results of Table 1 its shows once content of PVP and PEG was increase the encapsulation potency of the drug were increased. The appropriate reason was that the stabilize polar and non polar region and it hydrophobic phase control to the polar cluster once a tiny low polar molecule more they accumulate within the hydrophobic core of compound and from a inner connected network and it resulted increased the encapsulation of drug molecule (Table 1 and Figure 3).

On the basis of result obtained from particle size analysis and drug defense study performed and TEM of Dox- 4 transmission microscopy and examine the interior structure of molecule is a smaller amount than $100 \mathrm{~nm}$ (Figures 3 and $4 \mathrm{a}$ ) and it showed no indication of the other internal structure or spherical grain boundaries instead the particle consisted of a solid matrix having no sigh of pause separation of the drug and compound (Figures $4 a$ and $b$ ).

SEM image of n-DOX has been present in Figure $4 \mathrm{~b}$ that confirm they are circular in shape, smooth and well separated on the surface. It was observed the morphology of the particle was not affected by the amount of polymer and drug [22].

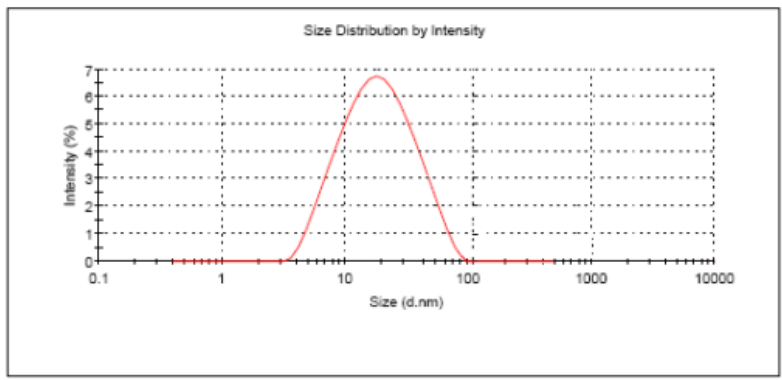

Figure 3: Size distribution of $n$ DOX

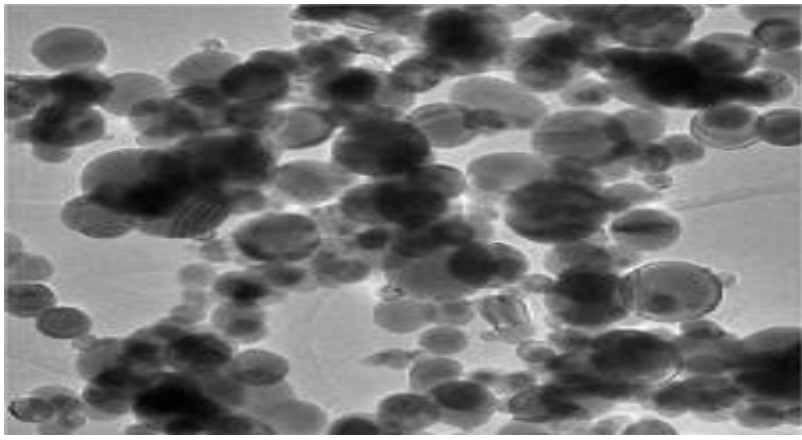

Figure 4a: TEMmicrograph of DOX.

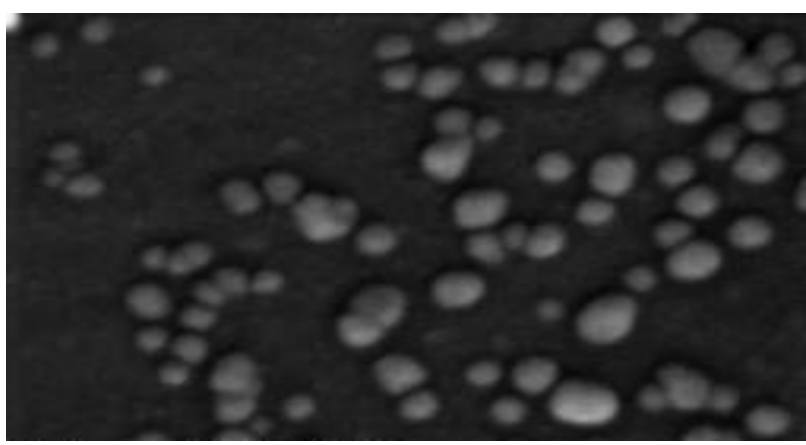

Figure 4b: SEM micrograph of DOX. 
Citation: Jain R, Sukla SK, Nema N, Panday A (2015) Drug Nano-particle: A Release Kinetics. J Nanomed Nanotechnol 6: 317. doi:10.4172/21577439.1000317

Page 4 of 6

Comparative in-vitro release profile and cumulative $\%$ drug release of this n-DOX and marketed sample (B-1) has been shown it Table 2 and Figure 6 . The System suitability parameter given in Figure 5 by HPLC under Dissolution study maximum drug release was observed is $\mathrm{n}$ - DOX it is $98.9 \%$ of drug in first $30 \mathrm{~min}$ (Figure 5).

To investigate the release kinetics of DOX from the n-DOX and B-1, release date was applied to zero order, first order, Hughchi, korsmeyer pepps, weibull, and baker-londale model and best fit was determined. Calculate the $\mathrm{n}$ value $\mathrm{R}^{2}$ and rate constant for each formulation.

It is known that if the values of ' $n$ ' in between 0-0.5 then it follows fickian diffusion and if ' $n$ ' values lies between 0.5-1.0 it supports nonfickian diffusion pattern. The result indicates that the regression analysis was done for all four brands. The Korsmeyer Peppas model show additional strict correlation values for various brands. To substantiate the diffusion mechanism, the info was match into Korsmeyer-Peppas model. The formulation of various brands showed sturdy one-dimensionality with slope locate with $\mathrm{n}=0.97$, indicating non-fickian release diffusion. the key benefits of those models are: a) The elucidation of the underlying mass transport mechanism; b) the chance to predict the impact of the device style parameters on the ensuing drug Release rate, therefore facilitating the event of latest pharmaceutical merchandise therefore the method concerned in drug Release kind nano-system theoretical justification for the Korsmeyer Peppas is seem to be applicable for any drug Release mechanism involving dissolution diffusion and mixed dissolution -diffusion rate restricted method Kinetics study of drug Release usually helpful in getting one or 2 physically meaningful parameter that square measure used for comparative purpose and relating the discharge parameter with vital parameter like bioavailability (Figure 6) [23].

The results showed biphasic profile describe the rapid initial rate decrease, followed by a more steady release rate. This behavior can be attributed to the 'burst' release, typical of hydrophilic matrices, occurring before the formation of the controlling gel layer on the matrix surface.

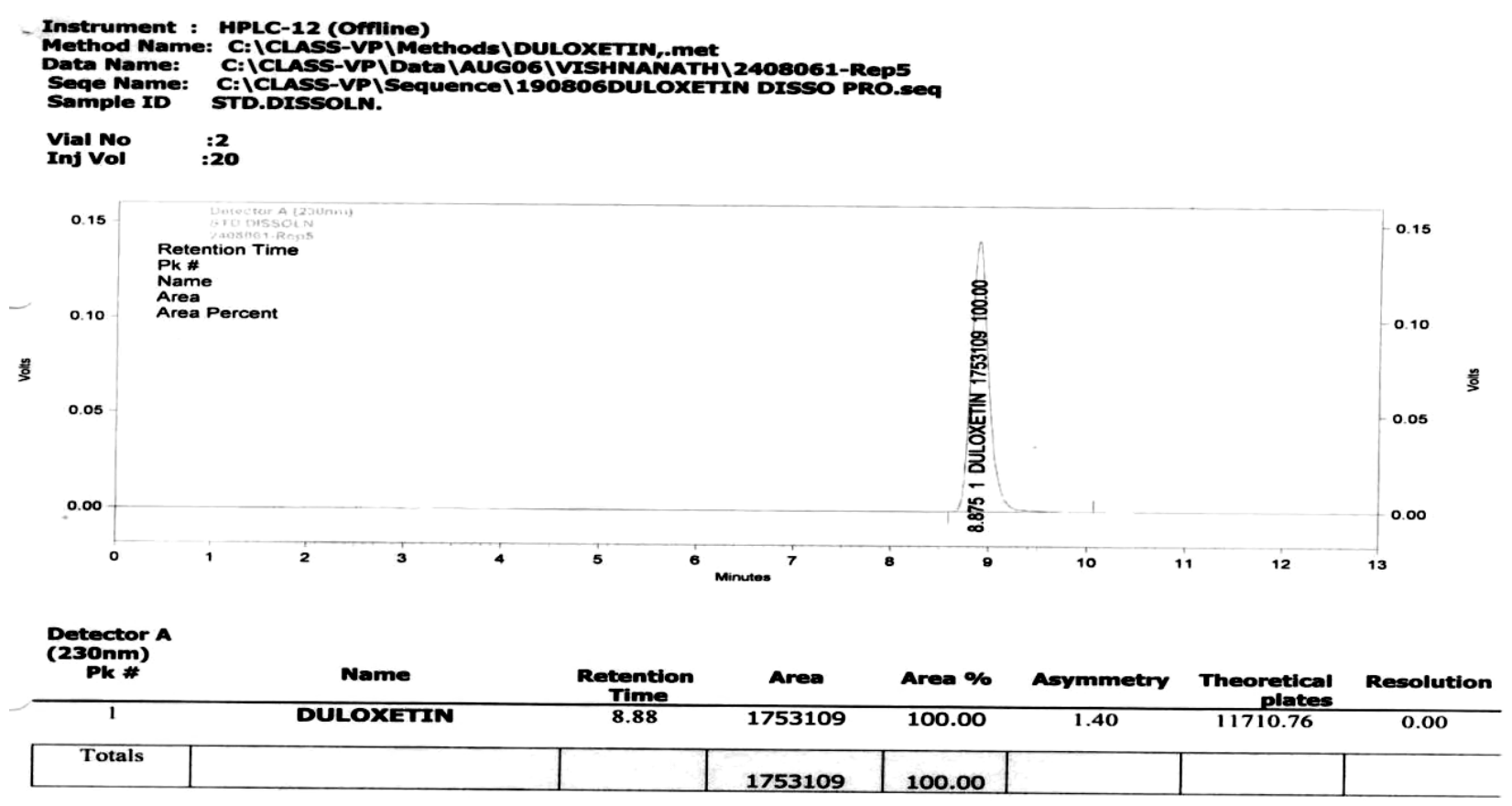

Figure 5: System-suitability chromatograph.

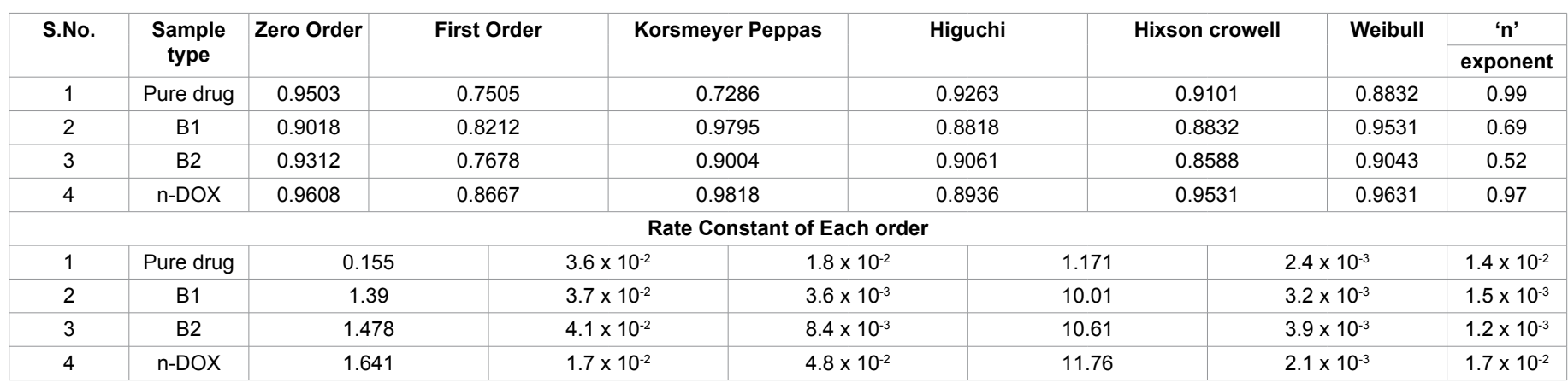

Table 2: Regression $\left(R^{2}\right)$ value and rate constant of all kinetic models. 


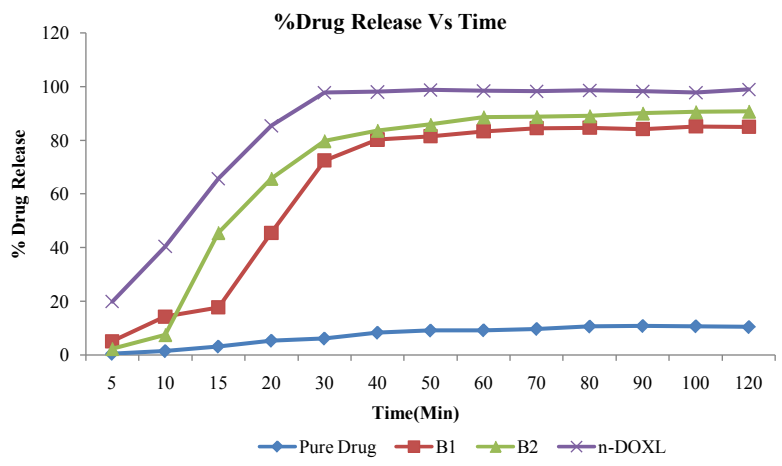

Figure 6: Cumulative \% Drug release $\mathrm{N}=6$ Units.

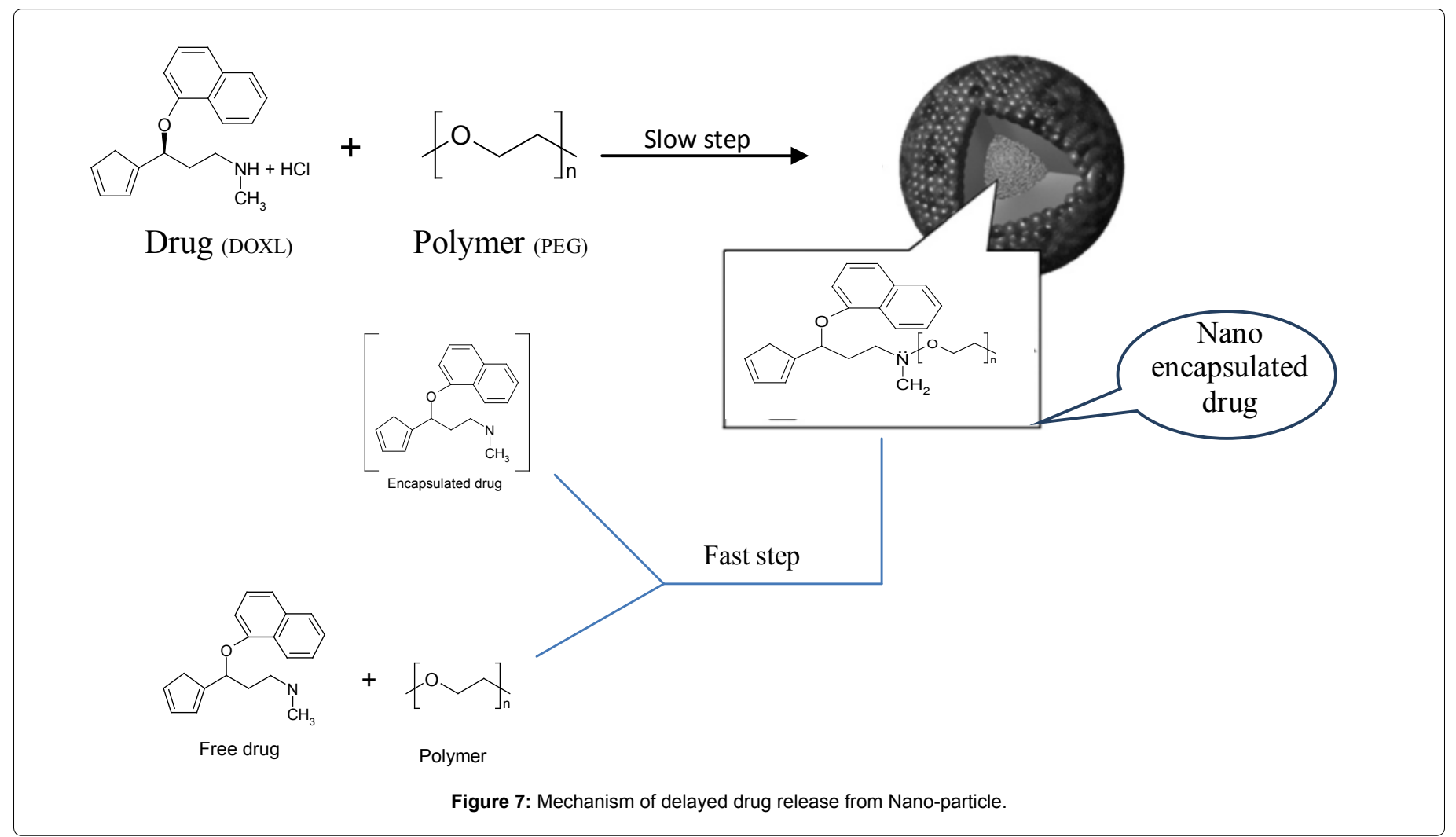

Drug release is also affected by particle size. Smaller particles have a larger surface area-to-volume ratio; therefore, most of the drug associated with small particles would be at or near the particle surface, leading to faster drug release. In contrast, larger particles have large cores, which allow more drugs to be encapsulated per particle and give slower release. Thus, control of particle size provides a means of tuning drug release rates (Figure 7) [24].

If a polymeric carrier is to be used, the next step is to design a type of polymeric structure that will permit obtaining the desire release condition in order to have an idea about the nature of interaction between the delayed release drug and the polymer the release kinetics well concluded as earlier. In first step it was found that drug molecule bounded by polymer by covalent bonding through two lone pair of electron of nitrogen atom. They form a compact structure of transient state. This state is in fast step and breaks into encapsulated drug and unused polymer as well as drug.

\section{Conclusion}

This work has been shown to be the comparative in-vitro bioavailability study Duloxitine Hydrochloride and Nano-particle of Duloxitine hydrochloride through the comparative dissolution study and also campier the release behavior of drug. Furthermore, this work is the first to show that the dissolution profiles follow Korsmeyer-Peppas model. Nan particulate drug delivery systems seem to be a viable and promising strategy for the biopharmaceutical industry. They have advantages over conventional drug delivery systems. They can increase the bioavailability, solubility and permeability of many potent drugs which are otherwise difficult to deliver orally by the nanoparticles. 
Citation: Jain R, Sukla SK, Nema N, Panday A (2015) Drug Nano-particle: A Release Kinetics. J Nanomed Nanotechnol 6: 317. doi:10.4172/21577439.1000317

\section{Acknowledgement}

I am thankful to the department of chemistry Dr. Hari Singh Gour University india providing an opportunity to work here as a research Scholar.

\section{References}

1. Murray ADC (1996) Lopez the global burden of disease. Determination of 266 Pesticide residues in apple juice by matrix solid-phase dispersion and gas chromatography-mass selective, Cambridge, Mass: Harvard University Press.

2. Detke MJ, Lu Y, Goldstein DJ, Hayas JR, Demitrack MA (2002) 60 mg once daily, for major depressive disorder: A randomized double-blind placebocontrolled trial. J Clin Psychiatry 63: 308-315.

3. Maio DS, Carrier RL (2011) Gastrointestinal contents in fasted state and postlipid ingestion: In vivo measurements and in vitro models for studying oral drug delivery. J Control Release 151: 110-122

4. Keller J (2015) Gastrointestinal Digestion and Absorption. In: Lennarz WJ Lane MD, editors. Encyclopedia of Biological Chemistry. Waltham: Academic Press: 354-359.

5. Tawfeek HM (2013) Evaluation of PEG and mPEG-co(PGA-co-PDL) microparticles loaded with sodium diclofenac. Saudi Pharm J 21: 387-397.

6. Barzegar-Jalali M, Alaei-Beirami M, Javadzadeh $Y$, Mohammadi G, Hamidi A et al. (2012) Comparison of physicochemical characteristics and drug release of diclofenac sodium-eudragit ${ }^{\circledR}$ RS100 nanoparticles and solid dispersions. Powder Technol 219: 211-216.

7. Adibkia K, Barzegar-Jalali M, Maheri-Esfanjani H, Ghanbarzadeh S, Shokri J, et al. (2013) Physicochemical characterization of naproxen solid dispersions prepared via spray drying technology. Powder Technol 246: 448-455.

8. Adibkia K, Barzegar-Jalali M, Nokhodchi A, Siahi Shadbad MR, Omidi Y, et al (2009) A review on the methods of preparation of pharmaceutical nanoparticles. Pharma. Sci 25: 303-314

9. Manilal KS (2011) Emeritus Professor, Hortus Malabaricus Project, Malbar Botanical Garden, Personal Communication.

10. Manivannan R, Parthiban KG, Sandeep G, Balasubramaniam A, Senthilkumar N (2010) Multiparticlate drug delivery systems: Pellet and Pelletization technique. Drug Invention Today 5: 233-237.
11. Vyas VU, Nagesh N, Pvan kumar M (2009) Pharmaceutical formulations comprising duloxetine.

12. Sinha VR Aggarwal A, Srivastava S, Goel H (2010) Influence of operational variables in multi-particulate delayed release systemsfor colon-targeted drug delivery of celecoxib using extrusion spheronization. A J Pharma 2: 102-109

13. Vaidhyamatam Aur Vaidhya sala, Thrissur, Kerala. Personal Communication.

14. Morterab R, Fiorilli S, Garroneb E, Vernea E, Onida B (2010) J Chem Eng 156: 184.

15. Gao L, Sun J, Zhang L, Wang J, Ren B (2012) Mater Chem Phys 135: 786.

16. He Q, Zhang Z, Gao Y, Shi J, Li Y (2009) Intracellular localization and cytotoxicity of spherical mesoporous silica nano-and microparticles. Small 5 : 2722-2729.

17. Moharana AK, Banerjee M, Panda S, Muduli JN (2011) Development and validation of UV spectrophotometric method for the determination of mesalazine in bulk and tablet formulation. Int J Pharm Pharmacol 3: 19-21.

18. Dare M, Jain R, Panday A (2015) Method validation for stability indicating method of releated substance in active pharmaceutical ingredient dabigatran etexilate mesylate by reverse phase Chromatography. J Chromatogr sep Tech 6. 263.

19. Jain R, Pandey A, Pandey SS (2009) Mechanism of dissolution of delayed release formulation of diclofenac sodium, Bulgarian. J Chemical Edu 18.

20. Nema N, Pandey A (2011) Determination of ketoconazole in different formulations by using polymeric surfactants under the influence of ammonium metavanadate. Oxidation Communication 34: 98-107.

21. Cohen DS, Erneux T (1988) Free boundary problems in controlled release pharmaceuticals. I: Diffusion in glassy polymers. SIAM J Appl Math 48: 1451-1455

22. Mehta AK, Yadav KS, Sawant KK (2007) Nimodipine loaded PLGA nanoparticles: Formulation optimization using factorial design, characterization and in vitro evaluation. Current Drug Delivery 4: 185-193.

23. Nema N, Jain R, Pandey A (2011) In-vitro release kinetic study of domperidon by using water soluble carrier polyvinylpyrrolidone. Natl Acad Sciences India 81: 289-294.

24. Jain R, Panday A (2015) A review of kinetics of nanoparticulated delayed release formulations. J Nanomed Nanotechnol 6: 304. 